\title{
Planning for Resource Recovery: Lessons from the California Experience
}

\author{
W. David Conn
}

The Resource Conservation and Recovery Act of 1976, which emphasizes resource recovery as a goal, provides for states or regional authorities to prepare comprehensive solid waste management plans. A review of the experience in California, where solid waste planning has been required since 1972 , shows that communities have generally hesitated to include resource recovery in their plans; this seems to be due largely to technological uncertainties, to the existence of economic and institutional biases against recovery, and to the lack of financial assistance for planning and implementation. Some of these obstacles may be overcome, at least in part, by provisions in the new federal act.
In a recent article in this journal, Greenberg (1977) provided planners with an overview of resource recovery options and suggested how, at the local level, they might assess the feasibility of specific resource recovery proposals. Since that article was written, passage of the Resource Conservation and Recovery Act of $1976(\text { RCRA })^{1}$ has given planners further cause to be concerned with problems of solid waste management (SWM) in general, and resource recovery in particular. A major provision of the act is for states or regional authorities to undertake comprehensive planning for solid waste management, giving consideration inter alia to "types of resource recovery facilities and resource conservation systems which are appropriate." The stated aims of the act include maximizing the utilization of valuable resources and encouraging resource conservation.

Whereas Greenberg's article considered how local

W. David Conn is assistant professor of environmental planning in the School of Architecture and Urban Planning, University of California, Los Angeles. His background is in chemistry and economics; present research interests include solid waste management and air quality planning. planning boards might judge the soundness of particular resource recovery proposals brought to them by "vendors, private interests, and branches of government," the present article relates to the extent and manner in which planners, through the medium of the newly required comprehensive plans, might be expected to take the initiative in identifying, evaluating, and preparing for the implementation of appropriate resource recovery systems.

Planners have already had an opportunity to take this initiative in California, where SWM planning at the county level has been required since $1972 .{ }^{2}$ How ever, despite the state's adoption of an explicit goalreducing the statewide annual tons per capita of residential and commercial wastes going to landfill by 25 percent between 1972 and $1980^{3}$ - a review of the SWM plans prepared by about half of California's fifty-eight counties ${ }^{4}$ has revealed little evidence of serious efforts to significantly increase the level of resource recovery within the next few years. It seems that several factors influenced the manner in which resource recovery was treated in the county plans including the lack of availability of resources for conducting the planning itself, the present uncertain state of resource recovery technology, and existing 
economic and institutional biases against resource recovery.

This article examines the California experience and considers how some of the obstades to planning for resource recovery in that state might be overcome by provisions in the new federal legislation.

\section{Reasons for promoting resource recovery}

Before examining the treatment of resource recovery in the California county SWM plans, mention should be made of the justification for the state's (or any other government entity) intervening to promote an increase in the recovery level over that resulting from largely market determined actions of local agencies and the private sector. This justification is provided inter alia by the widespread belief that market forces alone are unlikely to bring about the most socially desirable resource recovery level, for the following reasons."

1. The fact that many of the environmental and esthetic costs of alternative methods of waste disposal (such as bandfill) are generally left unquantified means that these methods tend to be underpriced relative to resource recovery.

2. Specific government policies (such as the favorable tax treatment given to the extractive sectors and regulated freight tariffs that favor virgin over secondary materials) may in some cases excessively encourage the extraction and use of virgin materials (and the generation of waste) while discouraging resource recovery.

3. A similar effect results from the fact that, although the extraction of virgin materials generally entails greater environmental costs than the recovery of secondary materials, the differential in costs is rarely reflected fully in the relative prices.

4. Many people feel that the actions of private individuals and firms in the marketplace do not adequately represent the preferences of society as a whole (and certainly cannot reflect preferences of unborn generations); thus, the social value of resource recovery as a means of conserving natural resources may not be fully realized.

\section{Resource recovery in the California county SWM plans}

The present author established a set of criteria relating to the treatment of resource recovery and then applied them in evaluating the California county SWM plans.

\section{Criteria for plan evaluation}

Was there a clear statement of goals? Although the state (through the Solid Waste Management BoardSWMB) had set a specific statewide goal for reducing the quantities of wastes going to landfill, with the intention that this should be achieved primarily by increased resource recovery, ${ }^{6}$ each individual county was not necessarily required to achieve the same recovery level. Thus, counties were left with some latitude in setting their own resource recovery goals. Not only should each plan have contained a clear statement of the chosen goals, but also the latter should have been translatable into operational criteria by which recovery and other options could subsequently be judged.

Was the waste stream adequately described? In planning any resource recovery system, it is essential to have detailed knowledge of the potentially recoverable resources in the waste stream. As specified in the guidelines issued by the SWMB (California SWMB $1974 \mathrm{a})$, the plans should have contained estimates of present and projected future quantities of waste generated in each county, together with estimates of composition (by material). Ideally, these should have been based on weighings and analyses performed locally (since waste generation rates can differ significantly from one location to another); however, at the very least, per capita generation factors (published by the California SWMB, 1974b) should have been used in conjunction with the appropriate population data.

Were all possible options identified and adequately described? In any planning exercise it is important to identify all the possible options, although there is little point in providing complete details of those that are clearly infeasible. In other words, it is reasonable to screen out some options prior to the detailed evaluation. For example, for many counties (particularly the rural ones) a back-of-the-envelope calculation would have sufficed to eliminate a number of socalled "high technology" options; these are the fully mechanized materials and/or energy recovery processes such as waterwall incineration or pyrolysis, which have very high capital and operating costs and are unlikely to be feasible except in installations that handle large quantities of waste. For those options remaining, however, consideration should have been given not only to their general characteristics but also to the detailed factors affecting their possible implementation in the county concerned. This required that more than superficial attention be given to the availability and accessibility of markets for recovered products, possible institutional problems, etc.

Was there a clear analysis of costs and financial feasibility? Many published figures for the costs of resource recovery systems are based on contractors' estimates for particular plants. However, in practice, costs will vary considerably from one location to another, depending on site conditions, the availability of markets, etc.; furthermore, they can change 
rapidly over time. While it might have been unreasonable to expect, at this level of planning, precise location- and time-specific quotations for each option under serious consideration, the plans should at the least have contained up-to-date estimates of the likely range of costs involved. To facilitate comparisons, a standard accounting format (such as that published by the California SWMB, 1975b) should have been employed, showing clearly which items were included in the costs and which were omitted. As specified in the guidelines, the plans should have demonstrated the feasibility of financing the chosen option(s).

Was there evidence that an evaluation had been carried out in accordance with criteria based on the county's specified goals? The criteria and evaluation process used in judging options should have been made apparent in each plan.

Were the steps for implementing the chosen option(s) clearly laid out? Not only should all phases of the plan have been programed on a time schedule (as specified in the guidelines), but also those responsible for taking particular actions (at least in the short term) should have been identified. Failure to do this would make it more difficult to monitor the plan's implementation and to ensure that all of the necessary steps were being taken. Consequently, inaction could more readily result from individuals being unaware of, or knowingly avoiding, their designated responsibilities.

Was there evidence that the public had been involved in the preparation of the plan? Since the plan could significantly affect the public in a number of ways (e.g., through impacts on taxes or charges for solid waste services, on land use, on business operations, etc., as well as on natural resource utilization and environmental quality), public involvement should have been an essential ingredient in the plan preparation process. The state guidelines had suggested the formation of a task force or steering committee that included public members, the holding of public hearings, and the use of various methods of informing the public about plan development.

\section{Results of the review of California SWM plans}

Statement of goals. Most, though not all, of the plans reviewed contained an explicit statement of goals relating to resource recovery. Two of the plans (San Francisco and Sutter-Yuba) called for a 25 percent reduction in per capita solid wastes going to landfill by 1980 , although there appeared to be an inconsistency in San Francisco's plan since it subsequently overlooked the numerical target and simply proposed to "substantially reduce landfill as a method of solid waste disposal by 1990." In most of the other plans that contained resource recovery goals, these were given a very general form. Typical examples were: "to promote the maximum possible recovery of materials and energy from the waste stream" (San
Benito); "to incorporate modern technology in the program of solid waste management, including full consideration of recovery, recycling, composting, and the use of solid wastes to produce energy where feasible" (Placer); "to encourage practices in solid waste management which are directed to and in support of the goal of the state of reducing the quantities of solid wastes now disposed of in sanitary landfills by 25 percent by 1980 through source separation and/or resource recovery" (Ventura). Note that the last did not commit Ventura County itself to a 25 percent reduction.

The problem with all of the more general resource recovery goals was that they were not translatable into precise criteria by which the available options could be judged. In practice this generally meant that the evaluations in most plans were based, explicitly or implicitly, on the criterion of "economic feasibility" (which almost invariably meant least cost), and that those goals which were not reflected in economic calculations tended to be overlooked.

Description of the waste stream. Very few counties weigh all (if any) of their municipal solid wastes and thus the quantities listed in the plans were in most cases estimated by combining the SWMB waste generation factors with local population data. Only a few counties gave detailed breakdowns of the composition of the waste stream, and these were generally based on the estimated average composition nationwide, as reported by the U.S. Environmental Protection Agency (1974a). The possibility of regional or local variations in composition (for example, resulting from the greater use of aluminum rather than steel cans for beverages in a particular area) was not explored.

Identification and description of options. In identifying options, most of the plans were quick to mention the many high-technology, fully mechanized systems for materials and/or energy recovery that are being promoted commercially and have received a great deal of attention from state and federal agencies; however, the plans were generally less complete in their coverage of low-technology alternatives such as household separation followed by separate collection of recyclable materials (an option that was omitted entirely from several plans).

Descriptions of identified options varied considerably, from those that were very detailed, to those that consisted of brief outlines only. Some plans (such as Glenn, Merced, and Monterey) contained virtually no descriptions at all. Unfortunately, in nearly all cases where descriptions were included, little or no apparent effort was made to link these to the particular county concerned; instead, they were generally based on existing literature ${ }^{7}$ (sometimes reproduced verbatim) which was either too general or referred to specific plants construted (or planned for construction) elsewhere. Many of the descriptions 
were superfluous since they related to systems that were clearly inappropriate for the counties in whose plans they appeared. Although they may have made for thicker (and, to some people's eyes, more impressive) plans, these descriptions contributed nothing to the planning process; omitting them would have served better.

In the same way that there was in general a failure to relate the descriptions of technological options to local circumstances, there also was very little detailed consideration of local markets for recovered products. Some cursory analyses of markets were reported (e.g., in the Del Norte, Kern, Placer, and Ventura plans), often based on spot checks of the current demand (and prices paid) for selected recyclable materials or fuels. However, as the U.S. Environmental Protection Agency (1976a) has pointed out, "superficial market studies are insufficient since only a detailed look at local industries can determine if they can use and will buy waste-based products. . . An adequate market study should identify a number of potential markets and determine the specifications, quantities, and price each would set for recovered products." The fact that a buyer currently exists (for example) for small quantities of materials brought to a recycling center does not necessarily assure a sustained market in the future for larger quantities of materials, possibly with entirely different specifications, produced in a full-scale recovery system.

Costs and financial feasibility. While many plans reproduced published figures for the actual, or more often the anticipated, costs of plants planned or constructed elsewhere, a few (such as the Solano, Los Angeles, and San Mateo plans) did make some attempt to examine the likely costs of a system installed locally, based either on a consultant or system designer's estimate or (in the case of several counties in the San Francisco Bay Area) on existing regional studies. ${ }^{8}$

However, in none of the plans reviewed was there a detailed exploration of the sensitivity of the overall economics of a plant to possible changes in particular costs and revenues. For example, careful examination of the Los Angeles plan revealed that the net cost per ton for a hypothetical 1,000-ton-per-day pyrolysis plant would be very sensitive to the revenue received from the sale of recovered materials and fuel, which in the analysis was estimated on the basis of very crude assumptions; in practice a slight rise in the assumed price for recovered oil could significantly affect the economics of the system. While the plan urged caution in developing firm conclusions based on a theoretical analysis, it made no attempt to identify the variables most likely to be significant.

Since none of the plans reviewed proposed the implementation of a high technology, capital intensive resource recovery facility in the near future, the question of how such a facility might be financed was not addressed in detail. Where resource recovery activities were proposed for early implementation, these invariably were of a type that had low capital and operating requirements and presented little or no financing problems.

Evaluation. In most counties it was apparent that resource recovery options had been selected (or more commonly rejected) on the basis of rough, back-ofthe-envelope assessments taking into account such factors as the size of the waste stream, the likely costs of recovery systems, the availability of potential markets, etc. In a few counties, more sophisticated evaluation procedures had been employed; however, since most of the goals for resource recovery had been phrased too vaguely for them to be translated into precise evaluation criteria, cost minimization was almost invariably the dominant (and usually the only) criterion actually applied. The Solano plan was exceptional in that options were explicitly assessed "first .. on strictly an objective evaluation of basic economics and then on a subjective evaluation of other intangible factors." A scoring system was used to rate the options in terms of their impacts on the environment, on safety, on public health, and on regionaliza-

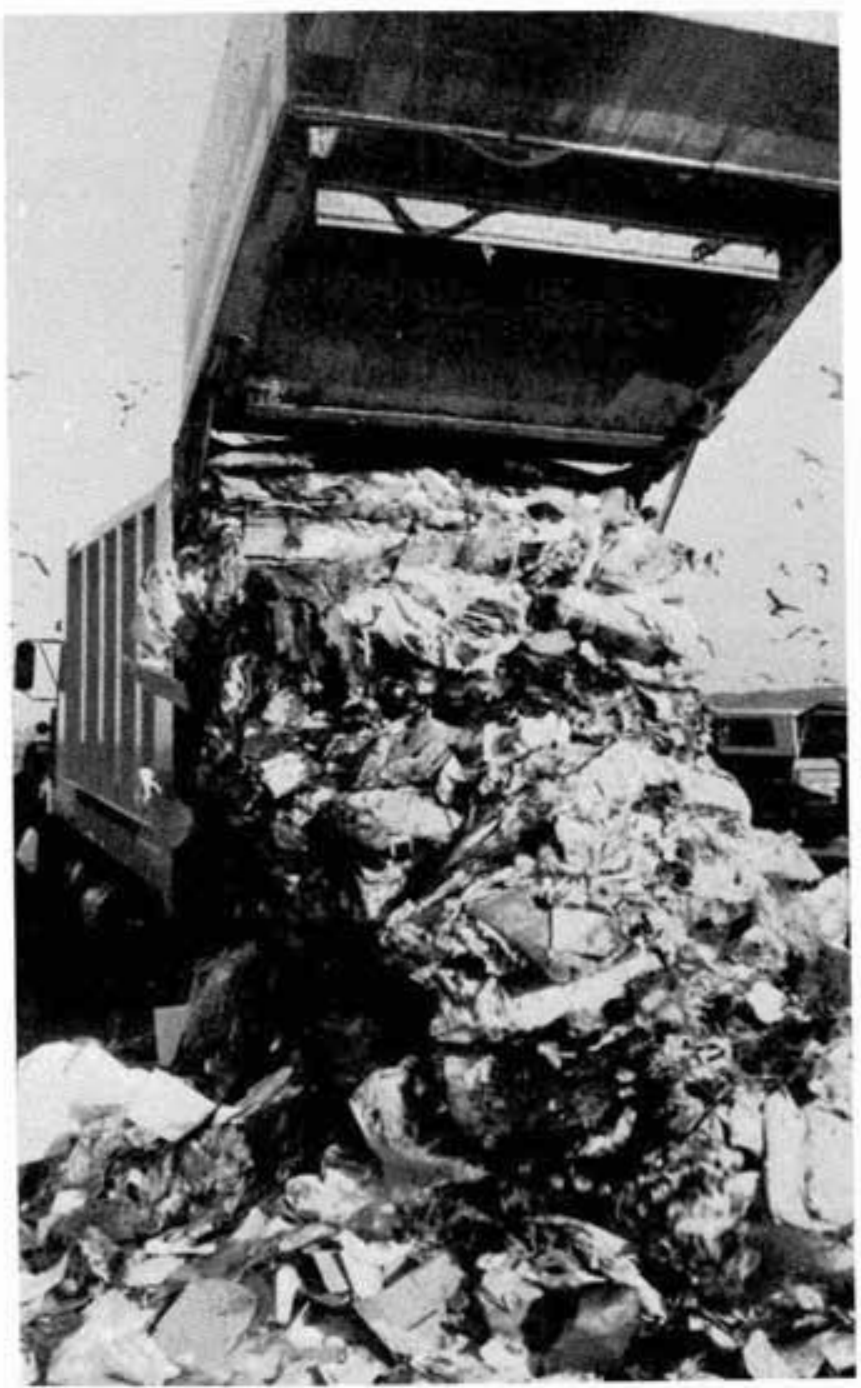


tion. The procedure was crude, but at least it represented an attempt to take these factors systematically into account.

Most plans made no claim that a detailed evaluation of full-scale resource recovery options (other than hand separation and recycling operations of minor significance) had yet been undertaken or completed. Instead, they referred to studies that were still in progress, promised for the future, or simply suggested as necessary next steps. For example, San Francisco's plan stated categorically that "a resource recovery program is feasible;" it referred to existing reports by consultants, but it provided virtually no details of their findings and merely promised an ongoing program of studies. The plan for Los Angeles contained a theoretical cost analysis comparing pyrolysis with landfill, but it then simply outlined the procedures for evaluating the feasibility of a particular resource recovery facility without actually carrying them out.

Implementation. Since few plans proposed the undertaking of any significant resource recovery activities in the short term, the attention given to implementation was sparse. Some plans scheduled further investigations of resource recovery possibilities in the future, but it was not always clear who would conduct these studies and how the results might be translated into action.

Public involvement in planning. It was rather difficult to judge, simply by reading the plan documents, the extent to which the public had been involved in the planning process. Many of the plans reported that an advisory committee and/or task force had been established with members representing a broad spectrum of interests (as suggested in the state guidelines), but it was not possible for the present author to determine whether these groups had been able to exert a significant influence on plan development. Some plans (such as EI Dorado, Santa Barbara, SutterYuba) documented efforts to keep the broader public informed about planning activities, through newspaper articles, open meetings, etc.; however, a few plans (such as Madera, Placer, Siskiyou) made no mention at all of public involvement, which meant that there was either an omission in reporting or, more seriously, a major inadequacy in the planning process.

\section{Summary and discussion}

The treatment of resource recovery in the California county plans can be criticized on many grounds. In most of the plans reviewed (with just a few exceptions): resource recovery goals were not sufficiently well defined; the quantities of wastes and perhaps more importantly their composition (determining the proportion of recoverable resources) were inadequately studied; the lists of options identified were incomplete (particularly with respect to lowtechnology possibilities); poor selectivity was shown in describing the options (with inadequate attention being paid to local circumstances); the likely costs of local implementation and the sensitivity of these costs to key variables were inadequately explored; and there was a failure to evaluate the options in a comprehensive and systematic manner. Many of the counties seemed to have prepared "plans for plans," providing only a very superficial overview of resource recovery alternatives while discussing the need for more detailed studies of possible markets, plant locations, costs, etc., to be conducted in the future. All of this indicated a lack of real commitment to resource recovery and made it apparent that the SWMB's goal of reducing the statewide per capita residential and commercial solid wastes going to landfill by 25 percent between 1972 and 1980 would not be met.

\section{Factors affecting the California experience}

As mentioned at the beginning of this article, several factors should be taken into account when reviewing the California experience, relating to the availability of resources for conducting the planning itself, the state of resource recovery technology, and the existence of economic and institutional biases against resource recovery.

Resources for planning. The 1972 state legislation that required each county in California to submit a solid waste management plan, consistent with state policy, to the SWMB by January 1, 1976, did not provide any resources (other than the technical assistance of the board's staff) for doing so. Thus the counties had to devote their own resources to meeting a state imposed requirement, and many (especially the less populated rural counties) were limited in the amount of qualified manpower, funds, etc., they were willing or able to divert to this purpose. At the very least it could be argued that the state should have avoided unnecessary duplication of effort by more thoroughly researching and evaluating alternative resource recovery technologies and providing this information in common to all counties before they began their planning.

The state of resource recovery technology. The reluctance of most counties to opt for high technology resource recovery facilities, at least in the short term, cannot be considered altogether unreasonable when it is realized that, despite earlier optimism regarding the development of mechanized materials and energy recovery systems, the only process to have been fully proven so far in full-scale, continuous operation is waterwall incineration; however, this technology may not be environmentally acceptable in many parts of California due to air pollution problems, and it is very expensive (especially when stringent emission controls are required). More promising are several 
variations of a process involving materials separation and the preparation of a refuse-derived fuel for combustion in an existing furnace (with appropriate modifications); full-scale plants have recently started operations in Ames, Iowa; Baltimore County, Maryland; and Milwaukee, Wisconsin. However, the longterm technical and economic viability of these systems has yet to be demonstrated. The development of pyrolysis has been slowed by unexpected technical problems (such as mechanical unreliability and difficulties in meeting air pollution standards, which largely contributed to Monsanto's withdrawal from its demonstration project in the city of Baltimore), while costs have soared (increasing, for example, from the originally anticipated figure of $\$ 4$ million for Occidental's demonstration plant in San Diego to a current estimate of \$14.4 million ${ }^{9}$ ).

In view of the technological and economic uncertainties involved (as well as doubts about the wisdom of undertaking a long-term commitment to feeding a highly capital intensive plant with huge quantities of waste, thereby removing any incentive to encourage the reduction of these quantities), and given that most local authorities are operating under particularly tight financial constraints (with solid waste projects generally afforded a low priority), it is understandable that most counties are unwilling to invest at this time in a fully mechanized system. It is in their interest to delay a decision until they can see how the new generation of plants will fare elsewhere.

On the other hand, there is less justification for their failure (in most cases) to give adequate consideration to the early implementation of low-technology resource recovery options, especially household separation with separate collection. The reference here is not simply to the establishment of neighborhood recycling centers where individuals can voluntarily bring their separated materials; while these have undoubtedly played an important role in educating the public about resource problems and giving them the opportunity to make a tangible contribution to the cause of conservation, they have not generally produced a significant and sustained reduction in the remaining waste stream. Such a reduction (of up to 30 percent, according to trials both in the United States ${ }^{10}$ and in Europe ${ }^{11}$ ) is likely to be achieved only if a large proportion of households can rely on regular collection of their recyclable materials, and are therefore encouraged to participate in the separation program on a regular basis; this is also essential if long-term agreements are to be signed for marketing the materials. As Seldman (1976) has pointed out, one feature of the approach is that it is labor rather than capital intensive, which may be a distinct advantage at a time of high unemployment. Economic and institutional biases against resource recovery. As already discussed in this article, it is widely believed that market forces alone are unlikely
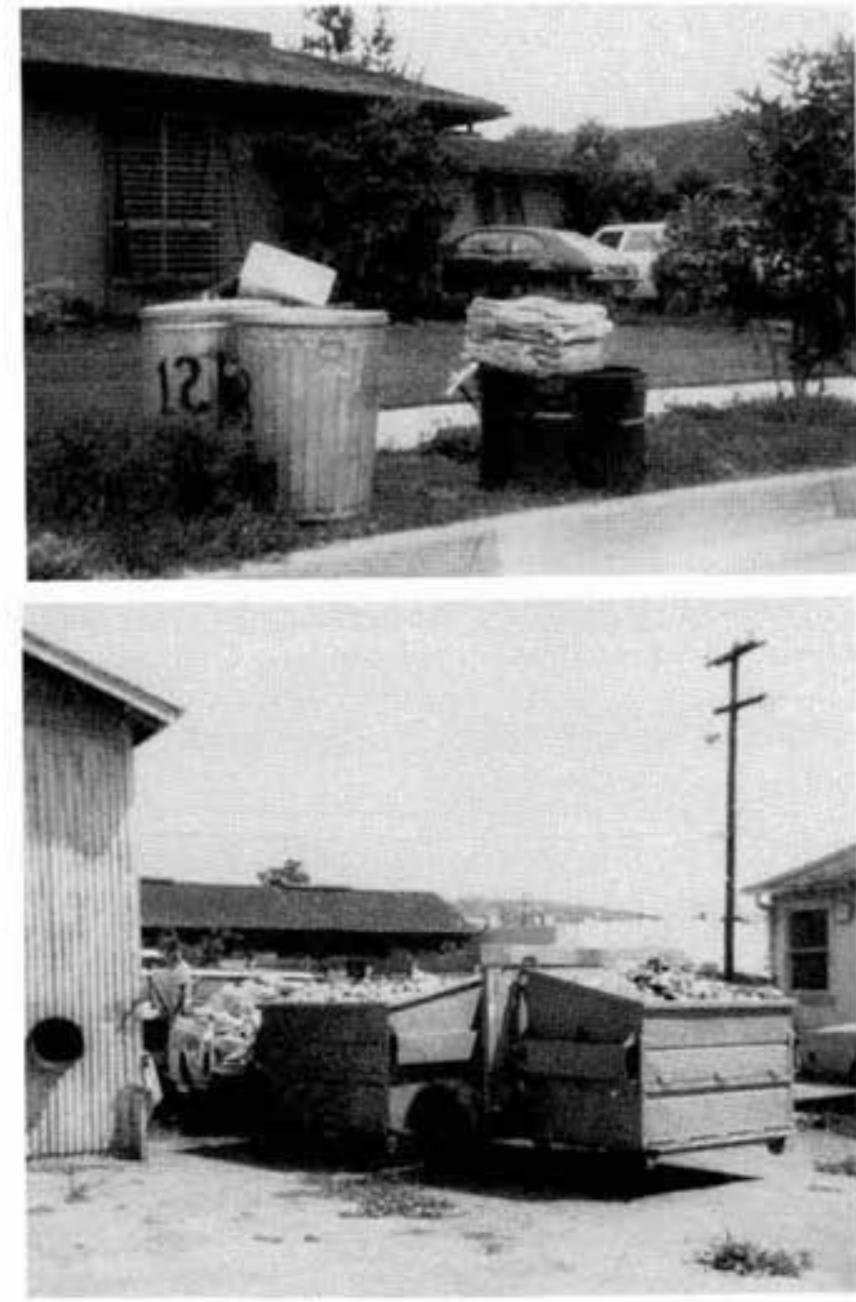

Photo: Rick Anthany. SCS Engineers

Newspapers, metals, and glass are separated for curbside pickup in San Luis Obispo, then stored in special containers awaiting shipment to recycling plants.

to bring about the most socially desirable level of resource recovery. In establishing its numerical goal for reducing the wastes going to landfill, the SWMB made a judgment on what this level should be. However, setting the goal did not in itself remove the existing economic and institutional biases against resource recovery; thus the counties found themselves having to produce plans that could be shown to be economically feasible under prevailing market conditions, while at the same time they were asked to strive for a goal that was based at least partially on nonmarket considerations.

It follows that the state should have acted rapidly to remove, or persuade the federal government to remove, as many as possible of the present biases against resource recovery. Furthermore, to the extent that resource recovery could be expected to produce benefits accruing to the state and/or nation as a whole, rather than to the individual counties, there was some justification for the latter to have been promised some form of financial assistance to make recovery more economically attractive. 
Of course, this reasoning does not provide the counties with an excuse for having failed (in most cases) to seriously investigate all available options that could have proved viable even under existing conditions. In addition, benefits that are not necessarily reflected in the economic accounts (such as reduction in the environmental impacts associated with sending wastes to landfill) may accrue directly to the local community itself; thus, as pointed out in the Los Angeles plan, "whether or not a given resource recovery operation must be profitable . . . to be acceptable is up to the community. Some may wish to operate programs which break even or operate at a loss, by subsidizing with public funds. A resource recovery program might be operated, then, as a public service rather than as a profit making activity."

\section{The Resource Conservation and Recovery Act of 1976}

It is appropriate to consider certain provisions of RCRA as they relate to resource recovery, in light of the preceding discussion. ${ }^{12}$

\section{Provision of planning funds}

RCRA potentially overcomes one major difficulty faced by the counties in California, in that funds are authorized to assist in the development and implementation of the new state and regional plans. Unfortunately, the amount that Congress has actually appropriated for solid waste activities in the 1977-78 fiscal year is considerably less than that authorized, ${ }^{13}$ and if this pattern is repeated in future years, the whole planning process could be placed in jeopardy.

\section{Appointment of technical assistance panels}

Another RCRA provision that should facilitate resource recovery planning is the appointment of resource conservation and recovery panels consisting of various technical, marketing, financial, and institutional specialists, to provide assistance to state and local governments at no charge. Greater confidence in planning will also result from the fact that in the past few years, since the California counties began the preparation of their state-mandated plans, resource recovery options have been subjected to ever increasing scrutiny at federal, state, and local levels. As the first generation of high technology materials and energy recovery plants go into full-scale operation, and as more communities experiment with low technology alternatives, the risks and uncertainties associated with the various options will inevitably diminish.

\section{Closure or upgrading of open dumps}

A provision that should make resource recovery options relatively more attractive in the eyes of local communities is the requirement of RCRA that open dumps be closed or upgraded within a specified time period. This will, in effect, mean that the price of land disposal (which will now have to be conducted in a more environmentally responsible manner) will more fully reflect the social costs involved; thus environmentally less damaging options, such as resource recovery, will appear less expensive in comparison.

\section{Stimulation of markets for recovered materials}

To assist in removing biases against resource recovery, RCRA directs the secretary of the Department of Commerce to provide for the development of accurate specifications for recovered materials (so that prospective purchasers can have a better knowledge of their characteristics and possible uses as substitutes for virgin materials) and to otherwise promote the growth of markets for the products of recovery systems. In addition, all federal agencies will (within two years) be required to procure "items composed of the highest percentage of recovered materials practicable consistent with maintaining a satisfactory level of competition," and those agencies that operate energy conversion facilities technically capable of using fuels recovered from wastes will have to use this capability "to the maximum extent practicable." Guidelines for implementing these provisions for federal procurement will be issued by the EPA administrator. The hope is that the federal example in making a commitment to the use of recovered products not only will provide a direct stimulus to the markets for these products, but also will lead to similar actions by other government agencies and private organizations.

\section{Support for research, development, demonstration, and education}

In common with preexisting federal solid waste legislation, RCRA authorizes the EPA to provide financial and other assistance for research, development, demonstration, and education programs relating to solid waste management, including resource recovery. An important provision is for the establishment of a resource conservation committee (composed of the EPA administrator, the secretary of Commerce, and other officials of high rank) which is directed to conduct a broad ranging investigation of economic, social, and environmental aspects of resource conservation, and to make policy recommendations to the president and Congress. One policy option to be examined is that of introducing a system of solid waste disposal charges on consumer products, the revenues thus raised being returned to local communities for use in financing resource recovery and other solid waste services on a continuing basis. The disposal charge concept has been discussed 
extensively elsewhere ${ }^{14}$ in essence, it would tend to make those responsible for designing and manufacturing the products that ultimately constitute the waste stream also responsible for paying the costs of handling-disposing of this stream (and thus causing these costs to be reflected in the prices of the products). An additional advantage of a charge system is that, by granting an exemption for the use of secondary materials in the manufacture of new products, it could be used to offset (at least partially) the present biases that tend to favor the use of virgin materials.

\section{Conclusions}

It appears from the California experience that, technical problems aside, the willingness of local communities to select resource recovery options may remain limited as long as existing biases in the marketplace tend to make them economically unattractive and while there is little provision for the communi- ties to receive financial assistance in return for pursuing the social benefits of recovery that accrue beyond their own boundaries.

As has been mentioned, RCRA does authorize financial assistance, but the initial appropriation has been small and future appropriations are uncertain; furthermore, there are restrictions on the uses to which the money may be put (for example, it may not generally be used either for construction or to subsidize the prices of recovered resources). Other RCRA provisions should lead to the early removal of some, though not all, of the market biases; however, the success of the act in promoting resource recovery may ultimately hinge on the ability of the new resource conservation committee to cause remaining biases to be removed and to ensure that an appropriate incentive structure is provided for local communities. It is therefore to be hoped that the activities of this committee will not go unnoticed, but will instead lead to prompt and effective action by the government.

\section{Author's note}

The author wishes to acknowledge the cooperation of those counties that provided copies of their solid waste management plans. Gay Muttersbach is thanked for her assistance in review. ing the plans. Donald M. McAllister, Ruthann Corwin, Keith Amundson, and Tom Clark kindly gave comments on earlier drafts of this article.

\section{Notes}

I. Public Law 94-580.

2. The Nejedly-Z'Berg-Dills Solid Waste Management and Resource Recovery Act of 1972 specified that "the primary responsibility for adequate solid waste management and planning shall rest with local government." In addition to the provision for county SWM planning, the act also required the newly formed solid waste management board (SWMB) to establish and maintain a comprehensive state solid waste management and resource recovery policy, with related programs intended to assist and guide local solid waste operations.

3. State Policy for Solid Waste Management, adopted by California State Solid Waste Management Board, December 20. 1974.

4. Many counties missed the original January 1, 1976, deadline for completing their SWM plans and, at the time of writing. a few plans have yet to receive final approval from the SWMB. In response to a request sent to all counties early in 1976 by the present author, approximately one-half of the counties sent copies of their draft or final plans (some in abridged or summary form). Although not all counties provided complete copies of their final plans, members of the SWMB staff have confirmed that the sample received can be considered reasonably representative of the total submitted to the board.

5. For further discussion see, for example, Goddard (1975). League of Women Voters (1972), Page (1973), U.S. Environmental Protection Agency (1974a).

6. Rather than recovering resources after they have entered the waste stream, an alternative method of reducing the quantity of wastes going to landfill is to decrease the rate at which they are generated in the first place. Although the latter approach, known as waste reduction, has been the subject of a committee investigation for the SWMB (Conn 1976 and 1977), the board's policy has in the past tended to focus primarily on resource recovery.

7. Commonly used sources of information on resource recovery options were Midwest Research Institute (1973), U.S. Environmental Protection Agency (1974b), California Solid Waste Management Board (1974c and 1975a).

8. Economic feasibility studies of various forms of energy recovery from Bay Area wastes have been conducted by the Stanford Research Institute and the Ralph M. Parsons Company (for Pacific Gas and Electric).

9. C. E. Kaufman, solid waste program manager, County of San Diego, personal communication, 1977.

10. See, for example, U.S. Environmental Protection Agency (1976b).

11. M. Tolstoy, Atervinnings system ASAB AB (Sweden), personal communication, 1976.

12. RCRA also includes major provisions relating to the management of hazardous wastes (bringing the latter under federalstate control). However, since different issues are involved, these provisions are not discussed in the present article.

13. The total sum appropriated for E.PA's solid waste activities in the 1977-78 fiscal year is $\$ 38$ million, of which $\$ 14.3$ million will be distributed to the states on a population basis to support not only SWM planning but also the development of hazardous waste programs and the compilation of an inventory of open dumps. The total appropriation is less than a quarter of the amount authorized in the act.

14. See, for example. Ackoff (1974), Bingham (1977), National Commission on Supplies and Shortages (1976), Smith (1977), U.S. Environmental Protection Agency (1974a and 1977).

\section{References}

Ackoff, R. L. 1974. Redesigning the future: a systems approach to societal problems. New York: John Wiley and Sons.

Bingham, T, 1977. An analysis of the allocative and distributive 
effects of a disposal charge on packaging. In Resource conserva lion: social and cconomic dimensions of recycling, eds. D, W. Pearce and I. Walter. New York: New York University Press; and London: Longman.

California Solid Waste Management Board. 1974a. Guidelines for the preparation of county solid waste management plans. Sacra. mento: SWMB, State of California.

1974b. Solid waste generation factors in California. Bulletin no. 2. Technical Information Series. Sacramento: SWMB, State of California.

1974c. Resource reconery system.s. Bulletin no. 3. Technica Information Series. Sacramento: SWMB, State of California.

1975a. Current status of resource recovery systems and procpses. Bulletin no. 5. Technical Information Series. Sacramento: SWMB, State of California.

1975b. Cost analysis of resource recovery systems. Bulletin no. 7, Technical Information Series. Sacramento: SWMB. State of California.

Conn, W. D., ed. 1976. Proposed policies for waste reduction in California. Sacramento: Solid Waste Management Board. State of California.

1977. Waste reduction-issues and policies. Resources Policy 3. March: 23-38.

Goddard, H. C. 1975. Managing solid uastes: economics, technology, and institutions. New York: Pracger.

Greenberg. M. R. 1977. Suggestions for evaluating resource recovery proposals. Journal of the American Institute of Planners 43. 1: $24-32$.

League of Women Voters. 1972. Recycle: in search of new policies for resource recouery. Washington. D.C.: League of Women Voters Education Fund.
Midwest Research Institute. 1973. Resource recoviery: the state of technology. Washington, D.C.; Council on Environmental Quality. National Commission on Supplies and Shortages. 1976. Government and the nation's resources. Washington, D.C.: U.S. Government Printing Office.

Page, T. 1973, Economics of recycling. In Resource consemation, resource recoutry, and solid waste disposal, Congressional Rescarch Service, Environmental Policy Division. Studies prepared for the committe on public works, serial no. 93-12. Washington, D.C.: U.S. Senate.

Seldman, N. N. 1976. Low technology versus high technology approaches to resource recovery. Second California Recycling Conference. Santa Barbara: California Resource Recovery Association.

Smith, F. L. 1977. Pollution charges-the practical issues. In Resource conservation: social and economic dimensions of recycling, eds. D. W. Pearce and L. Walter. New York: New York University Press; and London: Longman.

U.S., Environmental Protection Agency. 1974a. Second report to Congress: resource recovery and soturce reduction. Washington, D.C.: U.S. EPA.

1974b. Decision-makers guide in solid waste management. (2d ed. 1976) Washington, D.C.: U.S. EPA

1976a. Planning and overview; resource recovery plant implementation: guides for municipal officials. Washington, D.C.: U.S. EPA.

1976b. Source separation - the community awareness program in Somerville and Marblehead, Massachusetts. Washington, D.C.: U.S. E.PA.

1977. Fourth report to Congress: resource recovery and waste reduction. Washington, D.C.: U.S. EPA 